\title{
Added value of SPECT-CT imaging in the diagnosis of unilateral active mandibular hypercondylia in adult: A Case Report.
}

Fabrice FOKOUE ( $\sim$ fabricefokoue2017@gmail.com )

Centre Hospitalier Universitaire Hassan II - Fes

Sanae El Mselmi

Centre Hospitalier Universitaire Hassan II - Fes

Nadia Abaouz

Centre Hospitalier Universitaire Hassan II - Fes

Nadia Alaoui Ismaili

Centre Hospitalier Universitaire Hassan II - Fes

\section{Case report}

Keywords: Hypercondylia, Mandibular condylar hyperplasia, Bone scan, SPECT CT

Posted Date: February 11th, 2020

DOI: https://doi.org/10.21203/rs.2.23230/v1

License: (c) (i) This work is licensed under a Creative Commons Attribution 4.0 International License.

Read Full License 


\section{Abstract}

Mandibular hypercondylia is a rare and autonomous bone disease due to the excessive growth of the condylar cartilage. The radiological assessment following the clinical examination remains essential to the diagnostic orientation. Planar bone scintigraphy has been frequently used to assess the active or inactive nature of this situation. We report here the case of a patient whose diagnosis of active mandibular hypercondylia was retained due to the complement with SPECT / CT imaging, the planar bone scintigraphy being negative.

\section{Introduction}

Mandibular hypercondylia is a rare and autonomous bone disease due to the excessive growth of the condylar cartilage induced most probably by a disruption of the feedback loops between the different histological layers leading to a persistence of the multiplication of prechondroblastic cells.

It affects the overall development of the mandible and this condition is characterized clinically by a typical facial asymmetry, with a mandibular anatomy, disturbed occlusion, and a tilted occlusal plane [1]. Planar bone scintigraphy has been frequently used to assess the active or inactive nature of this situation $[2,3]$.

We report here the case of a patient whose diagnosis of active mandibular hypercondylia was retained due to the complement with SPECT / CT imaging, the planar bone scintigraphy being negative.

\section{Patient And Method}

This is a 43-year-old female patient, with no significant pathological history, who has had mandibular asymmetry for 10 years. She was directed to the nuclear medicine department for a scintigraphic evaluation of condylar activity following the diagnosis of left mandibular hypercondylia, revealed after a dental panoramic examination supplemented by a craniofacial diagnostic CT scan.

Bone scintigraphy is therefore realised in the patient in two stages: Acquisition of early, then late static images focused on the skull on the anterior and posterior face, then a tomoscintigraphy focused on the skull and coupled with a low dose CT scan (SPECT/ CT) between 0-10 min, then 2 hours after IV injection of $740 \mathrm{MBq}(20 \mathrm{mCi})$ of metastable Technetium 99-labeled Methylene Diphosphonate (MDP$99 \mathrm{mTC}$ ). The acquisition of images was performed with a Siemens gamma camera model Symbia T6 2010. The analysis was done using a visual and quantitative approach. A relative bone fixation of $55 \%$ or more was considered pathological.

\section{Results}

The planar bone scintigraphy did not show any asymmetry in radio tracer uptake in the early times (vascular and tissular), nor any abnormality in bone fixation in the late time between the two mandibular 
condyles (Fig. 1).

The complement by SPECT CT revealed an asymmetry of visual and quantitative fixation depending on the left mandibular condyle with an enlargement of left condyle in transversal, coronal and sagittal reconstruction images respectively thus allowing to conclude to an active left unilateral mandibular hypercondylia (Fig. 2).

\section{Discussion}

Mandibular hypercondylia was first described by Robert Adams in 1836, while describing a case of rheumatoid arthritis [4]. It is a disease of the temporal-mandibular joint resulting in excessive mandibular growth, most often unilateral. It affects the overall development of the mandible and results clinically in an unsightly and functional problem.

Mandibular hypercondylia usually occurs between 10 and 30 years, with a female-dominated sex ratio of $69.6 \%$ according to Vernex-Boukerma. Cases between the ages of 9 and 80 have been reported in the literature, and this discrepancy could be explained by delays in diagnosis $[1,4]$.

The exact pathophysiology of mandibular hypercondylia is unknown, but several etiological factors have been reported, including hyper remodeling of post traumatic mandibular condyle, joint infection, hormonal disorders, hyper vascularization of the mandibular condyle, intrauterine changes and genetic factors [5].

Although the diagnosis of certainty is only formally established on the histopathological exam, the radiological assessment following the clinical examination remains essential to the diagnostic orientation. Informations from a dental panorama and teleradiographic assessment, or diagnostic CT scan mostly allow the diagnosis of mandibular hypercondylia to be established.

The place of bone scintigraphy has a different interest from other imaging methods because it allows assessing the osteoblastic activity of the condylar cartilage $[2,3]$. In a context of clinical and radiological diagnosis of hypercondylia, a positive bone scan shows the active nature of the disease and allows therapy to be adapted.

The molecular imaging techniques commonly used are planar bone scintigraphy and single photon emission computered tomography (SPECT) which can be analysed quantitatively and qualitatively [5].

For most authors, SPECT will guide surgical management [6] and for others it could be used to measure residual activity after a condylectomy [7]. Condylectomy consists of a surgical excision of the cartilaginous cap, seat of the prechondroblastic cells, resulting in a definitive cessation of the pathological process. It is a key stage in the management of active hypercondylia [8].

In our study, all the modalities of bone scintigraphy were used. Planar imagery was negative at early and late times but the complement by SPECT / CT made it possible due to fusion images to correlate the 
hyperfixation area of the tracer with the area of hyperplasia on the CT scans, increasing thus the sensitivity of the bone scintigraphy and allowing retaining the diagnosis of an active unilateral mandibular hypercondylia.

\section{Conclusion}

SPECT / CT imaging appears to be the examination of choice for the assessment of condylar activity in mandibular hypercondylia in adults because it improves the sensitivity and specificity of bone scintigraphy.

\section{Declarations}

Ethics Approval and Consent: Obtained by the ethics committee of the Teaching Hospital Hassan II and the Faculty of Medicine and pharmacy of Fez.

Consent for publication: Obtained from the patient.

Availability of data and material: "Data sharing not applicable to this article as no datasets were generated or analysed during the current study".

Funding: No funding received.

Author's contributions: FF conceived of the study, participated in its design and wrote the manuscript. SM and NA participated in collecting personal data of the patient. NIA supervised the writing of this article. All the authors read and approved the final manuscript.

Acknowledgement: Special thanks to the EJNMMI Research team.

Competing interests: The authors declare that they have no competing interest regarding this article.

\section{References}

1. Gordeff A, Mercier JM, Delaire J. L'hypercondylie mandibulaire. Ses differents aspects cliniques et son traitement. Acta Stomatologica Belgica Vol.85, N 4,1988.

2. Regaieg, Ben Fredj. M, Charfi H, Sfar. R, Melki S et al. Hypercondylie unilatérale : valeur de la scintigraphie osseuse et de ses différents protocoles d'acquisition. Elsevier Médecine Nucléaire Vol 39, Issue 3, May 2015. P 32.

3. S. Choukry, J. Benouhoud, S.Zouine, S Nadi, A. Guensi. Apport de la scintigraphie osseuse dans les hypercondylies. Elsevier Médecine Nucléaire Vol 43, Mars 2019. P209.

4. Salagnac JM. Les hypercondylies mandibulaires : éléments de diagnostic différentiel Rev Ortho Dento Faciale. 36: 75-83, 2002. 
5. R. Nicot, G. Raoul, J.Ferri Hypercondylies. EMC Chirurgie orale et maxillo-faciale. Vol 14. N 4 Novembre 2019.

6. Wen B, Shen Y, Wang CY. Clinical values of 99Tm-MDP SPECT bone Scintigraphy in the diagnosis of unilateral condylar hyperplasia. Scientific World Journal 2014.

7. Pripatnanont $P$, Vittayakittipong $P$, Marmanee $U$ et al. The use of SPECT to evaluate growth cessation of the mandible in unilateral condylar hyperplasia. Int J Oral Maxillofacial Surg. 2005, 34: 364-8.

8. Delaire J. Le traitement des hypercondylies mandibulaires. Plaidoyer pour la condylectomie. AOS $1977,117,29-45$.

\section{Figures}




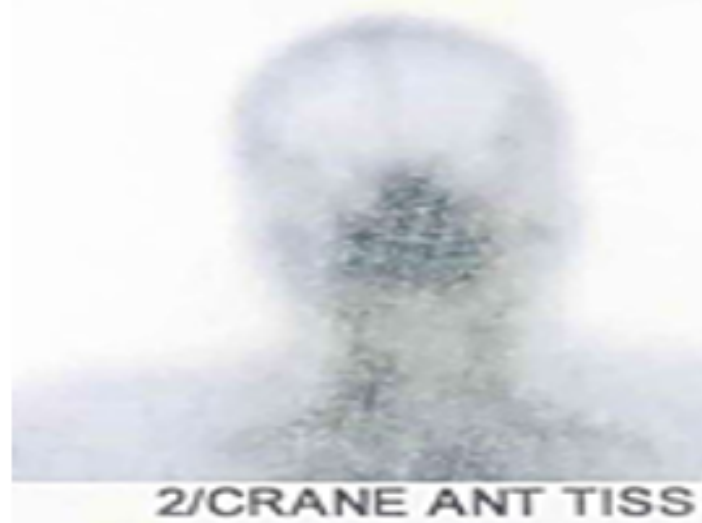

2./CRANE POST TISS

\section{Figure 2}

Planar bone scan: Static images focused on the skull performed between 0-10 min, then 2 hours after IV injection of $740 \mathrm{MBq}(20 \mathrm{mCi})$ of MDP-Technetium $99 \mathrm{~m}$. The exam did not show any asymmetry in radio tracer uptake in the early times (vascular and tissular time), nor any abnormality in bone fixation in the late time between the two mandibular condyles. 

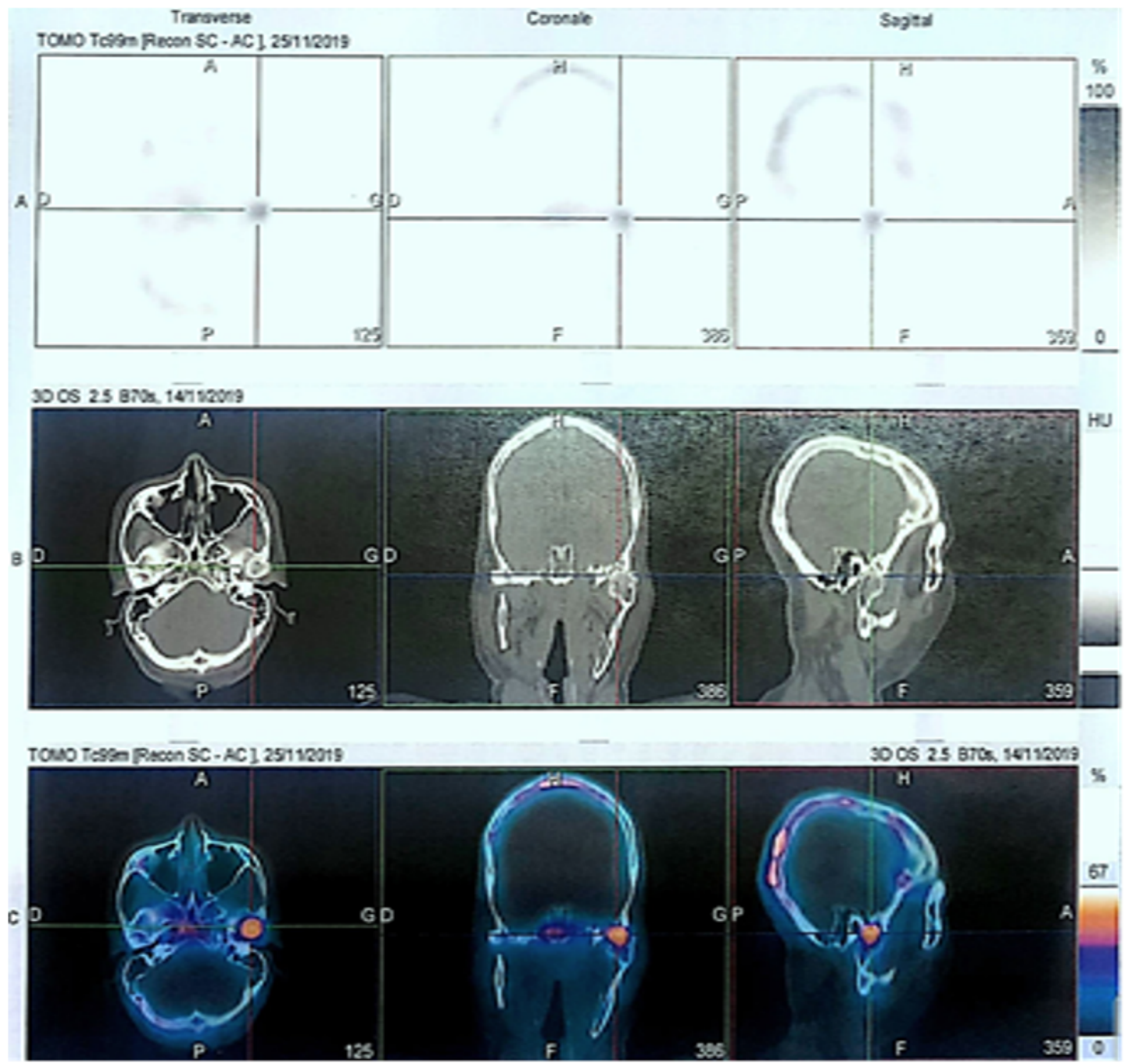

\section{Figure 4}

SPECT CT focused on the pathological area. The complement by SPECT CT revealed an asymmetry of visual and quantitative fixation depending on the left mandibular condyle with an enlargement of left condyle in transversal, coronal and sagittal reconstruction images respectively, thus allowing to conclude to an active left unilateral mandibular hypercondylia. 